\title{
Support technologies for deep and complex roadways in underground coal mines: a review
}

\author{
Hongpu Kang
}

Received: 2 April 2014/Revised: 4 May 2014/Accepted: 5 May 2014/Published online: 25 October 2014

(C) The Author(s) 2014. This article is published with open access at Springerlink.com

\begin{abstract}
Based on geological and mining characteristics, coal mine roadways under complex conditions were divided into five types, for each type the deformation and damage characteristics of rocks surrounding roadways were analyzed. The recent developments of roadway support technologies were introduced abroad, based on the experiences of supports for deep and complex roadways from Germany, the United States and Australia. The history and achievements of roadway support technologies in China were detailed, including rock bolting, steel supports, grouting reinforcement and combined supports. Four typical support and reinforcement case studies were analyzed, including a high stressed roadway 1,000 m below the surface, a roadway surrounded by severely weak and broken rocks, a chamber surrounded by weak and broken rocks, and a roadway with very soft and swelling rocks. Based on studies and practices in many years, rock bolting has become the mainstream roadway support form in China coal mines, and steel supports, grouting reinforcement and combined supports have also been applied at proper occasions, which have provided reliable technical measures for the safe and high effective construction and mining of underground coal mines.
\end{abstract}

Keywords Coal mines - Deep and complex roadways · Rock bolts $\cdot$ Steel supports · Grouting $\cdot$ Combined supports

\section{Introduction}

In underground coal mines, lots of roadways are driven to meet the requirements of transportation, ventilation and miner walking. The China coal output in 2013 amounted to $3.68 \mathrm{bt}$, of which the output of underground coal mines accounted for $85 \%$. The total length of new driven roadways each year in China state-owned coal mines amounts to $12,000 \mathrm{~km}$. Due to the huge scale of roadway projects, and the importance of roadway availability and stability on safety, output and profit of coal mines, the roadway support

\footnotetext{
H. Kang

Coal Mining and Designing Branch, China Coal Research Institute, Beijing 100013, China

H. Kang ( $\square)$

State Key Laboratory of Coal Mining and Clean Utilization, China Coal Research Institute, Beijing 100013, China

e-mail: kanghp@163.com
}

theory and technology are always the key research subjects in the field of ground control in coal mines.

With coal mining depth increasing, coal output growing, and mining areas expanding, the geological and mining conditions have changed considerably, which manifest the following three characteristics (Kang and Wang 2007).

(1) With coal mining activities extending to the depth, the proportion of deep mines becomes larger. As early as in 1980, the maximum mining depth of coal mines in Germany, former Soviet Union, Poland, Japan and France, had reached 1,000 m; in 1990s, the most mining depth in Germany was beyond $1,500 \mathrm{~m}$, those of Russia and Poland were 1,400 and $1,300 \mathrm{~m}$, respectively ( $\mathrm{Hu}$ et al. 2011). Some countries closed all or part of the underground coal mines, due to their great mining depth and high costs. The average mining depth of coal mines in China increases by $8-12 \mathrm{~m}$ per year, even faster in China eastern areas. At present, there are 47 coal 
mines in China with mining depth reaching $1,000 \mathrm{~m}$, of which, the Suncun coal mine of the Xinwen coal mining district in Shandong Province, is the deepest one with a depth of $1,500 \mathrm{~m}$. The increasing mining depth directly causes larger in situ stresses. The onsite measurements showed the in situ stresses in coal mines at depth beyond $1,000 \mathrm{~m}$ are more than $40 \mathrm{MPa}$ (Cai et al. 2008; Kang et al. 2010a, 2010b). Moreover, in some deep coal districts, the differential stresses are large, and the tectonic stresses are complicated. The high stress circumstances of deep coal mines have brought about a series of problems frequently encountered, including large deformation, lasting rheological behavior, bump, coal and gas outburst, and so on.

(2) With the coal mining areas expanding broadly, more and more coal mines with complicated geological conditions appear. On one hand, when mining the coal seams in the Tertiary period of the Cenozoic era, there exist very soft rocks, their uniaxial compressive strength is below $5 \mathrm{MPa}$, and some rocks are even weaker. These kinds of rocks are loose and weakly cemented, softening and swelling in the case of water, and strongly weathered to almost lose their strength. On the other hand, faults, folds, and karst collapse columns densely distribute in some coal districts, where beddings, joints, fractures develop maturely, leading to the low strength and poor stability of rocks. When driving roadways in extremely soft and broken rocks, roof collapse and rib spalling occur frequently, and the deformation of surrounding rocks is sensitive to various effects and disturbances (such as wind, water, quake and mining activity). Active support forms, such as rock bolts and cables, cannot exert their full functions due to the poor anchoring capacity, which leads to poor stability, strong deformation and damage, even the complete closure of roadways under extremely unfavorable conditions.

(3) With increased mining intensity, coal output and recovery, the proportion of roadways with large crosssection, roadways strongly affected by mining activities, and roadways retained or driven adjacent to the gob areas has enhanced obviously. Firstly, the increased volume and weight of mining equipment lead to increasing cross-section of roadways, for examples, the width of gateroads amounts to $5.5 \mathrm{~m}$, and the cross-section area amounts to $20 \mathrm{~m}^{2}$; the width of open-off cuts amounts to $10 \mathrm{~m}$, and the crosssection area to $35 \mathrm{~m}^{2}$. The increased cross-section causes greater difficulty in roadway support. Secondly, the multi-entry system has gradually replaced the single-entry system in coal faces with high output and high effectiveness or with high methane emission.
Each coal face often has 3-5 gateroads, or even more, to meet the requirements of ventilation and haulage (Kang et al. 2012). Some gateroads which serve two coal faces, are affected by mining activities two times. Besides the strong disturbances of mining activities, the long service time also contributes to the severe deformation and damage of these gateroads. Thirdly, the pillars decrease in size, even no pillar is needed, gateroads retained or driven adjacent to gob areas, are commonly applied (Bai et al. 2000; Kang et al. 2010c). Gateroads driven adjacent to gob areas leave a narrow pillar (3-5 m), which is severely broken and deformed after experiencing the mining disturbance. Gateroads retained along gob side experience the strong mining disturbances from the current face and the next face, especially after the current face is mined out, the strong roof sag causes large-scale deformation and damage.

Based on geological and mining characteristics, roadways under complex conditions were divided into five types (Kang and Wang 2007): (1) Loose and soft type. The surrounding rocks of roadways are loose, soft, water-softening and swelling, deform severely with a long time, and are sensitive to various circumstances and disturbances; (2) Broken type. The structural planes in the surrounding rocks of roadways develop maturely, coal and rocks are broken and instable; (3) High stress type. One sub-type is the roadways with depth more than $800 \mathrm{~m}$ and high in situ stresses, in which bumps and other disasters are easy to take place; the other sub-type is the roadways experiencing two-time or multi-time strong mining disturbances, causing high mining stresses and severe deformation. (4) Huge cross-section type. This type includes large cross-section roadways, open-off cuts and intersections; (5) Mixed type. This type involves the characteristics of two or more types stated above.

Many strata control methods have been developed to support the roadways under complex conditions in China and other countries. According to support mechanisms, roadway support forms can be divided into 5 types (Hudson and Harrison 2009; Kang et al. 2011a): (1) Supports acting on roadway surface. The resistance force of these supports acts on the surface of roadways, such as steel arches, props, cribs, shotcrete, cast-in-site concrete, and lining. To improve the loading states of steel supports, the gap between the steel supports and the roadway surface should be filled; (2) Rock anchorage. The components of this support not only act on the roadway surface, but also extend into the deep rocks and reinforce the rocks themselves, such as various rock bolts and cables; (3) Rock quality modification. This method improves the physical and mechanical properties of rocks, and enhances the strength and integrity of rocks, such as various grouting techniques; (4) Stress relief. This strata 
control technique attempts to improve the stress states of rocks, and decrease the stresses in rocks surrounding roadways, such as various destressing mining and stress control methods; (5) Combinations. Combinations of two or more methods stated above.

\section{Roadway support techniques at depth and under complex conditions abroad}

Many countries, such as Germany, UK, France, Poland, Russia, the United States and Australia, carried out researches on the theories and techniques of roadway strata control according to the local geological conditions. Three countries, Germany, the United States and Australia, were selected as examples to introduce the roadway support techniques under complex mining conditions.

\subsection{Roadway support techniques in German coal mines}

Germany has some of the deepest coal mines in the world, and the leading strata control technology for deep roadways (Shi et al. 2009, 2013). In the matter of roadway support technology, combined supports with yieldable steel arches and rock bolting, and backfilling beside the roadways and behind the steel arches are well studied and widely applied.

In the matter of the ground behavior law of gateroads, long term deformation monitoring had been carried out, and the effects of mining depth, rock properties, structural plane distribution and longwall retreating on the deformation and damage of rocks surrounding the gateroads were studied. The stress distribution and its variation in the rocks surrounding coal faces and roadways were calculated, and the formulae for estimating gataroad convergence were suggested based on the statistical analyses of monitoring data, laboratory tests and numerical results.

Based on the geomechanics properties of rocks surrounding roadways, a parameter representing the general characteristics of rocks was proposed to classify the stability of rocks. The surrounding rocks were divided into five grades, and each grade was subdivided into 2 subgrades. Roadway support patterns and parameters can be determined according to the rock grades. Rock bolts or yieldable steel arches are fit for stable rocks; combined supports with steel arches, rock bolts and cables, are necessary for the instable rocks.

Most roadways in German coal mines have an arch cross-section (except open-off cuts with a rectangular shape) with a large cross-section area about $30 \mathrm{~m}^{2}$. On one hand, large roadway cross-section is used to meet the requirement of ventilation; on the other hand, even if large

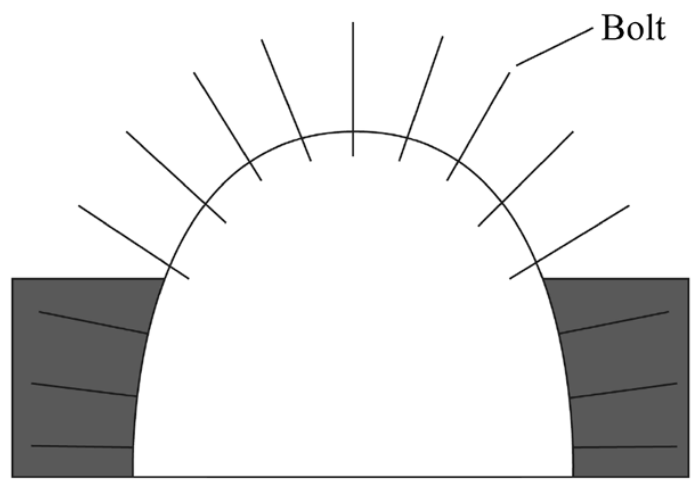

(a)

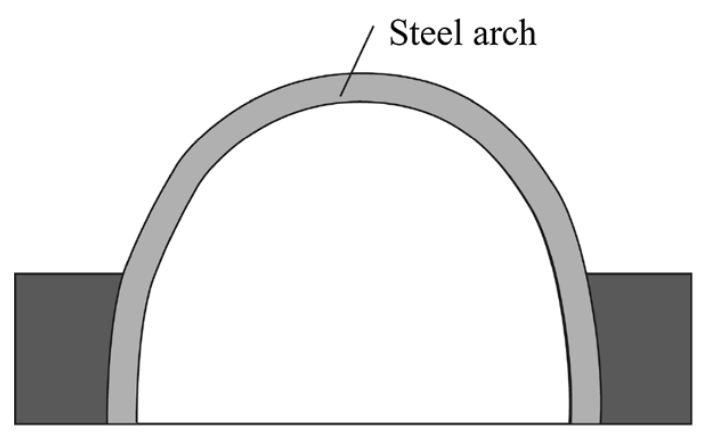

(b)

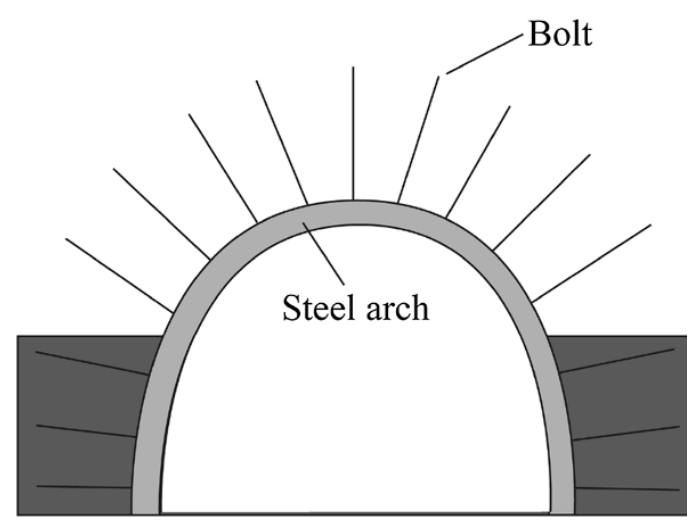

(c)

Fig. 1 Roadway support patterns in German coal mines. a rock bolting b yieldable steel arch $\mathbf{c}$ combined support

deformation happens, the reduced cross-section still meets the requirements of normal production. There are three mainstream support patterns, as shown in Fig. 1. Because the mining depth increases continuously, the proportion of roadways reinforced only by rock bolting (Fig. 1a) decreases year by year, that of roadways supported by combinations with yieldable steel arches and rock bolting (Fig. 1c) increases rapidly. Recently, the rock bolted roadways accounted for only $3 \%$, the roadways supported by yieldable steel arches (Fig. 1b) accounted for $65 \%$, and those supported by combined patterns accounted for $32 \%$. 
The steel supports used in German coal mines can be divided into four types according to their shapes: (1) U-shape steel arches (open in the floor); (2) U-shape steel arches with a yieldable inverted-arch component in the floor; (3) ring steel supports; (4) rectangular steel supports. The first type is applicable to various gateroads, the second type is applicable to haulage roadways, the third type is applicable to development roadways, and the rectangular support is applicable to the open-off cuts. In Germany, the importance of backfilling behind the supports is stressed especially in the interaction relations between supports and surrounding rocks. Backfilling behind the supports makes the steel supports fully contact with rock surface, increases the stiffness of media transferring resistance forces from steel supports to surrounding rocks, and greatly improves the performance of the steel supports. Testing results showed that backfilling can increase the bearing capacity of steel supports by more than one time.

A lot of researches in the rock bolting technology had been carried out in Germany. Resin capsules were invented in 1958, as a result, then resin bolts have been widely used in the world. To meet the need of deep roadways with large deformation, various extensible rock bolts were invented, involving the bolts made from the rebar with high elongation rate and those with slip components. The rock bolting is seldom used individually in German coal mines due to the large mining depth. In general, rock bolting is used with yieldable steel arches to form combined support system. In German coal mines, the standard rock bolt is made from the fully rolled threaded rebar with a diameter of $25 \mathrm{~mm}$, and a tensile strength of 700-800 MPa. The standard cables have a diameter of $23 \mathrm{~mm}$. There are two patterns of the combined support system, as shown in Fig. 2.

The first pattern (Fig. 2a) shows that rock bolts are installed following the excavation, then yieldable steel arch is set behind the working face 10-50 m, finally, backfilling is carried out between the rock bolts and steel arches. The second pattern (Fig. 2b) shows that steel arch is set following the excavation, then backfilling is carried out, finally, rock bolts are installed behind the working face 20-100 m. Using the first pattern, roof separation and rib fractures can be greatly reduced due to the active support action of rock bolts, therefore, the convergence of roadways can be decreased to less than half of that of roadways supported only by yieldable steel arches. Using the second pattern, the convergence of roadways is close to that of roadways supported only by yieldable steel arches, and the delayed installation of rock bolts results in poor performance. To improve the support performance for the second pattern, rock bolts should be installed before large deformation appears.

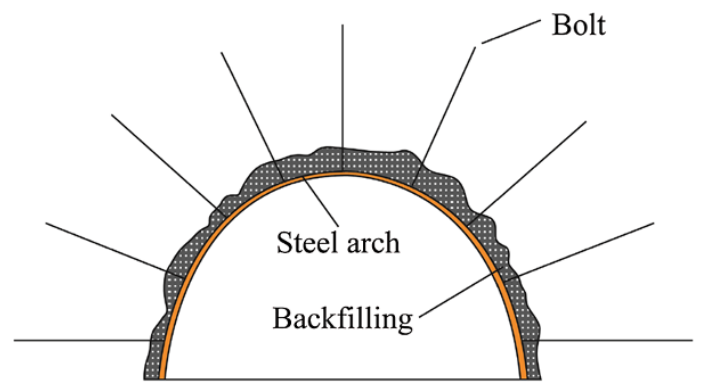

(a)

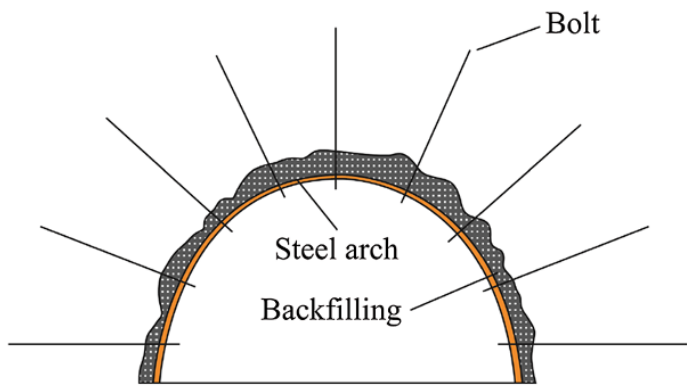

(b)

Fig. 2 Combined support patterns in German coal mine roadways. a rock bolts and steel arch $\mathbf{b}$ steel arch and rock bolts

\subsection{Roadway support techniques in American coal mines}

The United States began to use the rock bolting techniques earlier than most countries in the world, and applied rock bolting as the primary roof support (Peng and Tang 1984). The United States owns advanced rock bolting techniques, and consumes more than 80 million rock bolts each year.

The United States had developed a classification system for coal measures, called CMRR (Coal Mine Roof Rating), which involves following affecting factors: stratified thickness of immediate roof, shear strength of weak plane, rock compressive strength, number of roof layers, rock sensitivity to water, water content, and so on. According to CMRR, roof can be classified into three types: weak roof, medium roof and strong roof. Many coal mines in the United States carried out coal pillar design and rock bolting design on the basis of CMRR.

Rock bolts applied in the United States can be divided into many types: rock bolts with pretension and without pretension; point-anchored bolts and fully-grouted bolts; headed bolts and threaded bolts. Special rock bolts, including various cables and bolt trusses, are applicable to special geological conditions.

In early 1950s, the first expansion shell anchor was invented in the United States, which led to a fast development of rock bolting. Since resin capsules were invented, fully grouted resin bolts were widely used. In late 1970s, combination of expansion shell anchor with resin capsules (Fig. 3), provided a feasible approach to install bolts with high pretension. 


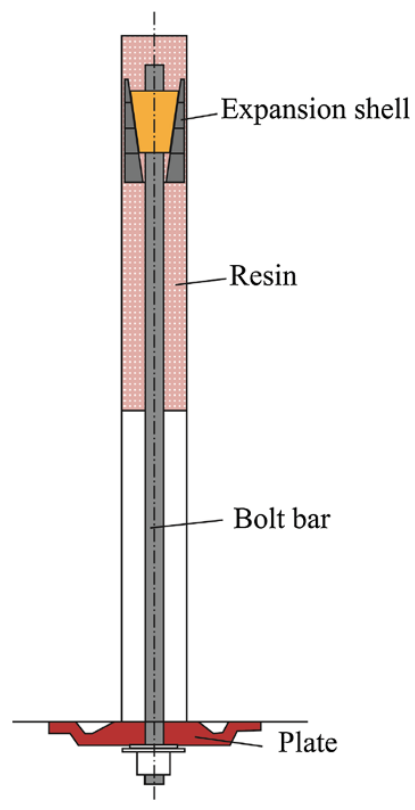

Fig. 3 Rock bolt anchored by expansion shell and resin capsules used in the United States

Under complex roof conditions, the function of rock bolt pretension was greatly emphasized in the United States (Song and Stankus 1997). Some American researchers thought that rock bolts with high pretension and suitable length and density could restrain roof separation, which has been taken as the guideline to design optimum bolting parameters. At present, the bolt pretension used in American coal mines is generally $100 \mathrm{kN}$, accounting for $50 \%-70 \%$ of the bolt yield load. The rock bolts with high pretension have improved the roof stability and greatly reduced roof collapses.

\subsection{Roadway support techniques in Australian coal mines}

Rock bolting is widely used in Australian coal mines, of all the roadway support methods, fully grouted resin rock bolting is the first choice (Gale et al. 1992). Before the rock bolting design, complete and systematic geomechanics tests and evaluations should be carried out. In-situ stress measurements showed the horizontal stresses are larger than the vertical stresses, and the maximum horizontal stresses are 2-4 times the vertical stresses. According to the characteristics of stress distribution around roadways, the main reason of roof damage was considered as the shear failure and lateral dilatation under high horizontal stress condition (Gale and Blackwood 1987), as shown in Fig. 4. Rock bolts provide shear resistance and axial restraining, which prevent roof from shear deformation and lateral expansion, keep a comparatively high residual horizontal stress in the roof to maintain its stability.

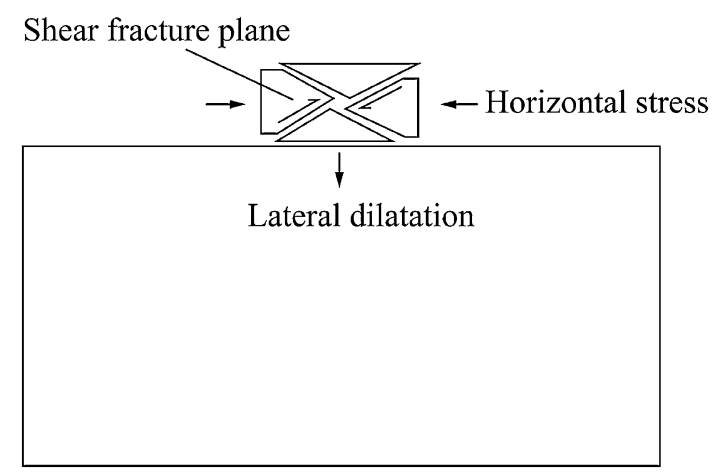

Fig. 4 Sheared roadway roof due to high horizontal stress

The fully grouted resin bolts with high strength and stiffness (AT bolts) are most widely used in Australian coal mines. The diameter of AT bolts is $22 \mathrm{~mm}$, and the lengths of bolts in roof and in sides are usually 2.4 and $1.8 \mathrm{~m}$, respectively. In general, AT bolts are used with $\mathrm{W}$-shaped straps and steel wire meshes. To meet the requirements of greatly deformed roadways, rock bolts with higher strength were developed, and the yield strength of rebar is $770 \mathrm{MPa}$ with a yield load of $260 \mathrm{kN}$ and a broken load more than $300 \mathrm{kN}$. Many kinds of flexible bolts and cables were also developed. The flexible bolts are made of high strength steel strand with a diameter of $23.5 \mathrm{~mm}$, a broken load of $580 \mathrm{kN}$, and a length of 6-8 m. It deserves to be specially reported that three kinds of self-boring rock bolts anchored by injection resin were developed in Australia, including general self-boring bolts anchored by injection resin, retractable self-boring bolts, and pretensioned self-boring bolts (Gray et al. 2010), which have provided an effective approach to reinforcing soft and broken rocks.

Field monitoring is considered to be of great importance in Australia, and rock bolting design based on field monitoring data was first applied in Australian coal mines (Villaescusa and Schubert 1999; Hutchinson 2000). The initial rock bolting design is put forward on the basis of the collected geomechanics data, and the design revision should be done according to the information collected from field monitoring during practices. If the roof separation is beyond the critical value, extra supports should be added to maintain the safety of the roadways. The main monitoring devices include two-point tell-tale, extensometer and gauged bolt.

\section{Roadway support techniques at depth and under complex conditions in Chinese coal mines}

The roadway support technology in China had gone through a history of timbering, lining, steel arch and rock bolting. After studies and practices for many years, rock 
bolts and cables have been the mainstream support method, however, there are still many other supports in use, such as steel arches, grouting and combined supports.

\subsection{Rock bolting}

Rock bolting in Chinese coal mines had gone through a process from low strength, high strength, to high pretension and extra high strength. The rock bolts used in early time were mechanical anchored bolts, point-anchored bolts, and split-set bolts, which were of low strength and stiffness, applicable to roadways in simple geological conditions and used in a limited scope. In 1995, rock bolted gateroads accounted for only $15 \%$ of total gateroads in Chinese coal mines. During 1996-1997, the Australian rock bolting technology was introduced, and additional researches and tests had been conducted based on the local geological and mining conditions, which obviously improved the level of rock bolting technology in China. The new technology, materials and methods, such as rock bolts made of deformed rebar with high strength and anchored with fullcolumn resin, the dynamic bolting design method, and the pretensioned resin cables with small boreholes, were widely applied in some coal districts, good support performance and economic benefits had been achieved. To tackle the roadway support problems at depth and under complex conditions, the rock bolting technique with high pretension and extra high strength was developed since 2005, which can not only control the roadway deformation, but also greatly increase the roadway driving rate. The modern support design thought with high strength, high stiffness, high reliability and low density were realized. At present, rock bolted gateroads in state-owned medium-tolarge coal mines accounts for about $70 \%$, even over $90 \%$ in some coal districts, and rock bolting has been the first choice of roadway support forms in coal mines.

\subsubsection{Rock bolting theories}

While rock bolting techniques are fast developed, lots of achievements have also been made in rock bolting theories. Based on lots of theoretical analyses, laboratory tests, numerical simulations and underground tests, the intrinsic nature of rock bolting has deeply been understood, which has promoted the development of rock bolting techniques (He et al. 2004).

Many rock bolting theories were proposed on the basis of interaction between bolts and rocks. Besides the traditional bolting theories, such as suspension, composite beam and reinforced arch, there are also the theories based on the broken zone around a roadway (Dong et al. 1994; Jing et al. 1999) and surrounding rock strength enhancement (Hou and Gou 2000). Three modes can be identified: (1) passively suspending the rocks in broken zones; (2) forming some structures in the anchored zone (such as a beam, a layer, an arch or a shell); (3) improving the mechanical performance and stress states in the anchored zone. Based on lots of researches, it was found that the action mode 3 is the most important intrinsic function of rock bolting.

Rock bolting mechanism is different from that of supports acting on the roadway surface. As rocks basically belong to non-continuum, the method used for continuum is not applicable in analyzing the functions of rock bolting. To fully exert the function of rock bolts, enough anchoring force is necessary, moreover, spreading the bolt resistance force into the rocks is also important. The non-continuous deformations, caused by separation, slip, fracture opening and new-born cracks, are the key factors to prevent the bolt resistance force from spreading into rocks. Lots of underground practices have shown that rock bolts should be installed with enough pretension as soon as the roadway is excavated, the initial separation of rocks can be restrained, and the bolting performance is best (Zhang and Gao 2004; Kang et al. 2007a). However, if rock bolts are installed in broken and separated rocks, even the bolts were heavily loaded, the bolting performance is poor. Therefore, the bolting theory with high pretension and extra high strength was proposed (Kang et al. 2007b, 2009c), the cores of which emphasize the decisive roles of bolt pretension and its spreading into rocks on bolting performance. The rock bolting with high pretension and extra high strength can effectively reinforce roadways once for all without twice or more supporting.

A series of new interaction curves between bolts and rocks were depicted based on testing data (Kang et al. 2009a), as shown in Fig. 5. The horizontal line at the top and the inclined line on the left side, represent the material without strength and the ideal elastic continuum, respectively. Curve 1 represents passive rock bolts with low pretension, the load on which is low with poor performance close to the case without support; curves $2-4$ lie between

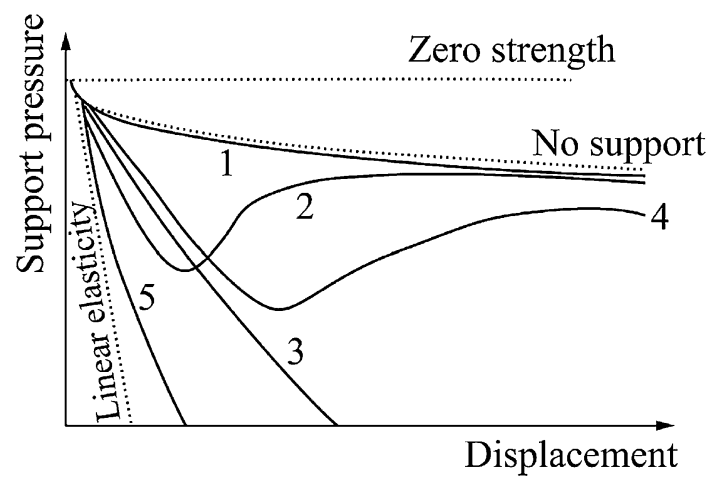

Fig. 5 Interaction curves between bolts and rocks 


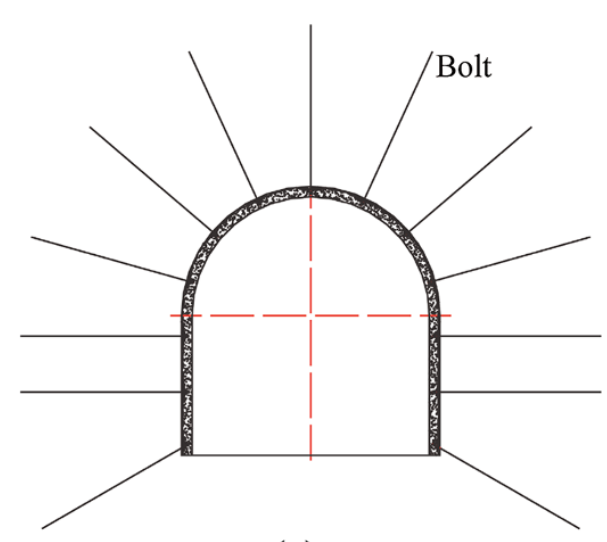

(a)

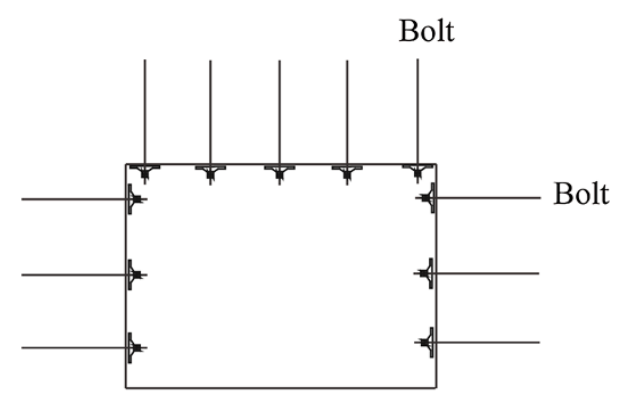

(b)

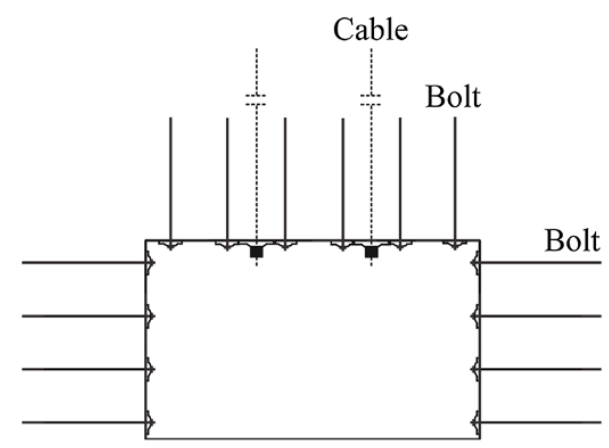

(c)

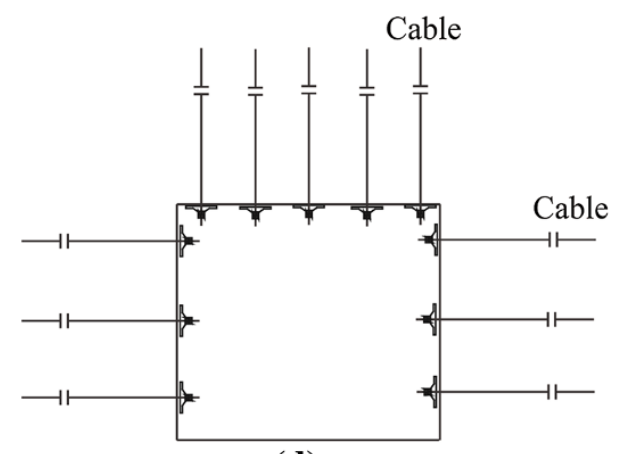

(d)

Fig. 6 Rock bolting patterns used in Chinese coal mines. a rock bolts and shotcrete $\mathbf{b}$ rock bolts $\mathbf{c}$ rock bolts and cables $\mathbf{d}$ whole cables curve 1 and 5, the common characteristics of these curves are that the bolts are pretensioned below the critical value, and fail to control the initial separation of rocks. Curve 2 represents that the load on bolts increases fast after installation, when the load reaches the broken strength, bolts will break and fail to support; Curve 3 represents that the load on bolts increases fast after installation, then tends to level off when reaching a constant value, and the rocks tend to be stable with large displacements; Curve 4 represents that the load on bolts reaches the maximum value, then decreases fast until residual anchoring force, and rocks will be instable; Curve 5 represents the bolts with high pretension and extra high strength, which can effectively control roadway deformations, result in small displacement difference in anchored zone and small variation of loads on bolts.

\subsubsection{Rock bolting design methods}

Based on the characteristics of roadways in coal mines, the dynamic and informational rock bolting design method was proposed (Kang 2002). This design method has two distinct characteristics: firstly, the bolting design is not completed once for all, but a dynamic process; secondly, the design fully utilizes the information collected in every period. This design method includes five steps, i.e. on-site investigation and geomechanics evaluation, initial design, field monitoring, information feedback and modification, daily monitoring. On-site investigation includes a series of tests on rock strength, rock structure, in situ stress, and anchoring performance, and so on; geomechanics evaluation and rock classification offering reliable data for the initial design. The initial design is conducted with numerical simulations and empirical rules to determine appropriate parameters. Then underground practices are carried out according to the initial design, the roadway displacements and loads on bolts are monitored in detail, and the initial design is validated or modified according to the monitoring data. To guarantee the roadway safety, daily monitoring is still necessary when the roadway is formally driven.

The general rock bolting patterns in Chinese coal mine roadways are shown in Fig. 6, including rock bolts and shotcrete (mainly used in permanent roadways), rock bolts, rock bolts and cables, whole cables. When designing a rock bolting system, the mutual match of different components is very important to the integral bolting performance. The strength of plates and nuts should be compatible with that of bolts, the cohesion strength of resin capsules should be compatible with those of bolt rebar, and the mechanical performances of straps and wire meshes should match 
those of bolt rebar. The bolts with high pretension and extra high strength should be matched with high strength arched plates, high strength nuts, efficient anti-friction washers, W-shaped straps with high strength and large covering area, wire meshes with high strength and stiffness. Otherwise, if any components fail, the integral bolting performance will be affected, even the whole bolting system will be destroyed. In addition, the patterns, parameters and mechanical properties of rock bolts and cables should match each other to make the most of their reinforcement functions.

\subsubsection{Rock bolting materials and components}

Rock bolting materials had experienced a developing process from low strength, high strength, to extra high strength. Rock bolts made of Q235 smooth steel rods were ever widely used in Chinese coal mine roadways, and are still applied in some simple geological conditions nowadays. To adapt to roadways at depth and under complex conditions, a series of materials for high strength bolts were developed (as shown in Table 1). The profile and parameters of deformed rebar were optimized to improve anchoring performance. The special rebar for rock bolts was developed with the strengths amounting to high and extra high grades (Kang et al. 2007b, 2009c). At the same time, a series of resin capsules, W-shaped and M-shaped straps were developed to form the high strength resin bolting system. These bolting materials have been widely used in Chinese coal mines.

As for pretensioned cable bolting techniques, the special cable strands with high elongation rate and supreme strength were developed to be used in roadways under complex conditions (Kang et al. 2009b, 2011b). A new structure of $1 \times 19$ strands was applied, which can greatly improve the cable broken force and elongation rate. To match bolt strength and installation, there are a series of strands with various diameters of 18, 20, 22 and $28.6 \mathrm{~mm}$. The broken load of the 28.6-mm diameter strand can reach $900 \mathrm{kN}$ with an elongation rate of $7 \%$, which are larger

Table 1 Mechanical properties of bolt rebar

\begin{tabular}{lllll}
\hline Brand & $\begin{array}{l}\text { Nominal } \\
\text { diameter } \\
(\mathrm{mm})\end{array}$ & $\begin{array}{l}\text { Yield } \\
\text { strength } \\
(\mathrm{MPa})\end{array}$ & $\begin{array}{l}\text { Tensile } \\
\text { strength } \\
(\mathrm{MPa})\end{array}$ & $\begin{array}{l}\text { Elongation } \\
(\%)\end{array}$ \\
\hline Q235 & $14-20$ & 235 & 380 & 25 \\
BHRB335 & $16-22$ & 335 & 490 & 22 \\
BHRB400 & $18-22$ & 400 & 570 & 22 \\
BHRB500 & $18-25$ & 500 & 670 & 20 \\
BHRB600 & $20-25$ & 600 & 780 & 18 \\
\hline
\end{tabular}

than that of $1 \times 7$ strand with the same diameter. The cable pretension can amount to $300 \mathrm{kN}$.

\subsubsection{Rock bolting monitoring}

As to rock bolt monitoring techniques, many kinds of instruments were developed to measure roadway convergence, roof separation, displacements in deep surrounding rock, loads on bolts and cables (Ju 2000). During recent years, advanced online monitoring systems used for roadways were developed. The system can collect underground monitoring data, transfer them to the surface station, monitor and analyze the data in real time.

There have been a lot of achievements in evaluating the underground support performance and roadway safety on the basis of monitoring data. Many feedback parameters, such as roof separation limits, rock bolt and cable load limits have been proposed, which are very important to evaluate roadway stability and revise rock bolting design.

\subsubsection{Case study}

The maingate $1202 \mathrm{E}$ in the Xiezhuang coal mine of the Xinwen coal mining district was a typical deep entry with the buried depth of 1,150-1,200 $\mathrm{m}$ and the maximum horizontal stress of $34.6 \mathrm{MPa}$. The thickness of the coal seam was averagely $2.4 \mathrm{~m}$, and its compressive strength was $12 \mathrm{MPa}$. The immediate roof was sandy shale with a compressive strength of 35-40 MPa and maturely developed horizontal bedding planes in it. The cross-section of the maingate was a rotated trapezium with a width of $3.7 \mathrm{~m}$, a medium height of $3 \mathrm{~m}$ and an area of $11.1 \mathrm{~m}^{2}$.

The maingate were designed to be reinforced by rock bolting system with high pretension and extra high strength. The bolts were $2.4 \mathrm{~m}$ long with a $25-\mathrm{mm}$ diameter and a broken load of $400 \mathrm{kN}$, anchored by resin capsules, and pretensioned to a load of $80 \mathrm{kN}$. W-shaped straps and wire meshes were used to protect the roof and the sides. The row spacing was $1,000 \mathrm{~mm}$ with a bolt spacing of $900 \mathrm{~mm}$ in roof, $1,100 \mathrm{~mm}$ in up-sides and $800 \mathrm{~mm}$ in down-side in one row.

The profile of the bolted maingate is shown in Fig. 7. The roof-to-floor convergence was $281 \mathrm{~mm}$, the side-toside convergence was $173 \mathrm{~mm}$, the roof sag was $40 \mathrm{~mm}$, and the floor heave was $241 \mathrm{~mm}$, which were decreased by $69.8 \%, 77.8 \%, 79.5 \%, 67.2 \%$ respectively, compared with those of the original bolting design. The roof separation was only $5 \%$ of the original value, the rocks surrounding the maingate were integral and stable. The rock bolting system with high pretension and extra high strength effectively controlled the severe deformation of the entry at depth, and provided a viable support method for deep roadways (Kang et al. 2010d). 


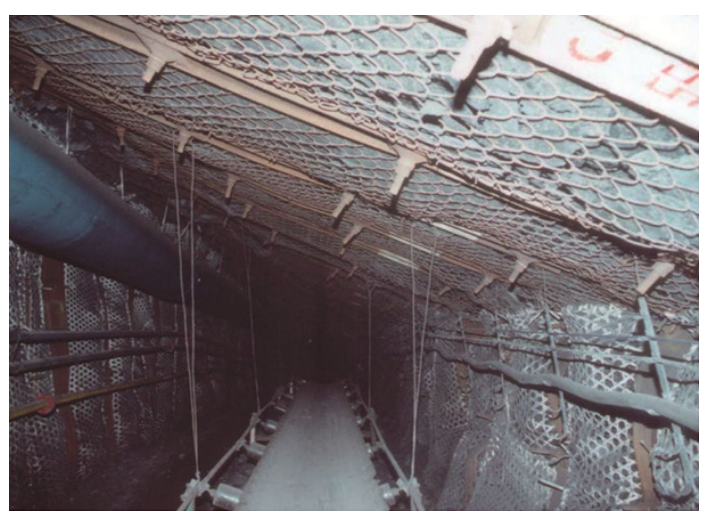

Fig. 7 Profile of bolted maingate with depth over 1,000 $\mathrm{m}$ in Xinwen coal mining district

\subsection{Steel supports}

In addition to rock bolts, steel supports are also important types for roadway support in Chinese coal mines, although they cannot provide active setting force to control the initial deformation and damage of rocks surrounding roadways. For roadways under some complex conditions, such as roadways in soft and broken rocks with poor anchoring performance not meeting bolting requirements; roadways surrounded by water-bearing, water softening and swelling rocks; deep roadways suffering high stresses and creep effect; roadways suffering strong mining disturbances and squeezing surrounding rocks; roadways in the bottom coal seam with gob as roof in the close-spaced multi-seam coal mining, and so on, steel supports are irreplaceable. In recent year, some achievements have been made in steel supports, some new models of steel supports have been developed, and the mechanical performance, structure and accessories of steel supports have been improved (Hou et al. 2013).

\subsubsection{Traditional steel supports}

Traditional steel supports can be divided into rigid and yieldable types according to their working performances (as shown in Fig. 8).

3.2.1.1 Rigid supports Rigid supports themselves are not yieldable, or slightly yieldable. Only when the steel supports punch into the floor, the wooden blocks in the joints of steel supports deform, and the steel supports deflect, limited displacements appear, therefore, rigid supports are applicable to roadways with small displacements.

Rigid supports are usually made from I-steel with a simple structure and an easy processing technology. There are three kinds of standard I-steel, Nos. 9, 11 and 12. Rigid supports have various shapes, such as trapezium, arch,

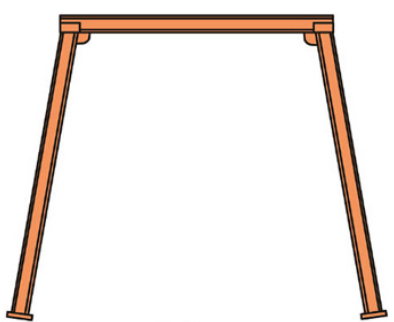

(a)

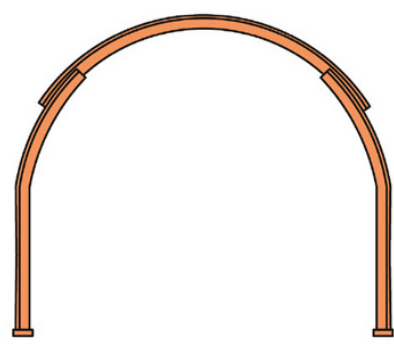

(b)

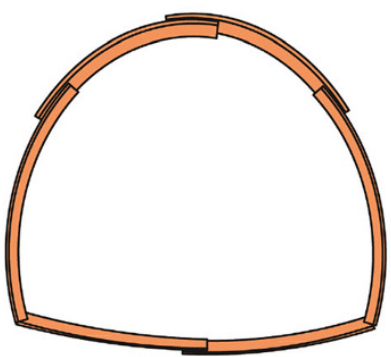

(c)

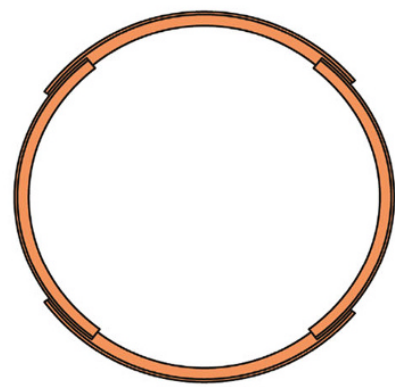

(d)

Fig. 8 Types of traditional steel supports. a trapezium rigid support b yieldable steel arch c yieldable horseshoe-shaped support $\mathbf{d}$ yieldable ring support

enclosed type. Trapezium supports (Fig. 8a) are widely used in gateroads. Steel rigid arches have various patterns: supports with an arch roof beam and two trapezium legs, supports with an arch roof beam and two arc legs, supports with an arch roof beam and two straight legs, which are applicable to different roadway conditions. Enclosed supports are not widely used, applicable to main roadways suffering high stresses. 
3.2.1.2 Yieldable supports Yieldable supports can be divided into three types by shape, that is arch, trapezium, and circular types. The yieldable steel supports most widely used in Chinese coal mines are U-shaped yieldable steel supports. U-shaped steel has a good cross-section shape and reasonable geometric parameters, and can retract easily when two parts overlap together. As long as the design is reasonable, good mechanical performance of steel supports can be acquired. The U-shaped steel widely used for yieldable supports in Chinese coal mines are U25, U29, and $\mathrm{U} 36$.

The connecting element is the key part to make steel supports yieldable. The steel support should maintain certain resistance force when it retracts, which can not only accommodate some rock deformation, but also restrain too large rock deformation to keep roadways stable. To meet the requirements mentioned above, the mechanical performance of the connecting element is very important. Any connecting element contains a lock unit and a friction unit. The lock unit binds the overlapping part of two segments in the support and offers compressive force. When the steel support overcomes the frictions between two segments of U-shaped steel and the connecting element, it will retract. According to the locking units, the connecting elements can be divided into bolt and wedge types. Bolt connecting elements can be subdivided into three types: a U-shaped bolt with clamping plate, double U-shaped clamping plates, and pushing bolt. Wedge connecting elements can also be subdivided into three types: wedge block (single-wedge or two-wedges), ear-shaped wedge, and buckled wedge.

A yieldable steel arch is composed of a roof beam, legs, and connecting elements (Fig. 8b). The roof beam is an arc structure, generally consisting of one or two segments. There are two types of legs: the first one consists of an arc segment in the upper part, and a straight segment in the bottom part; the other one consists of all curved segments. Yieldable steel arches can be divided into three-segment, four-segment, five-segment and more segment types according to the number of segments, in which, threesegment and four-segment types are used widely.

The yieldable trapezium support, compared with the yieldable arch support, behaves poor mechanical performance. However, it still has some advantages under certain conditions: no damage to roof, high utilization ratio of cross-section area, simple structure, easy processing and transportation. When the horizontal stress is not high, and the roadway cross-section is pretty small, yieldable trapezium supports can be applied.

The yieldable circular supports are also called the yieldable enclosed supports, which include horseshoe-shaped (Fig. 8c), circle-shaped (Fig. 8d), and square- or rectangular-shaped types. The yieldable arches and trapezium supports stated above are open in the floor, and cannot

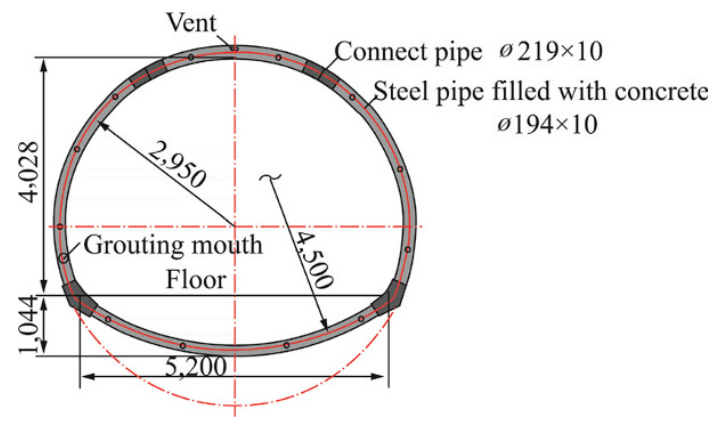

Fig. 9 Structure of steel pipe support filled with concrete ( $\mathrm{Li}$ et al. 2013)

control the floor deformation. The yieldable circular supports forms an enclosed ring, which can not only increase their bearing capacity, but also restrain the floor heave effectively. These yieldable circular supports are applicable to roadways in soft rocks with high stresses and large deformation, especially large floor heave.

3.2.1.3 Accessories for steel supports To fully exert the bearing capacity of steel supports and enhance their stability, it is very important to improve the contact condition between rocks and steel supports. Accessories for steel supports include tension rods, lagging, wire meshes and backfilling.

The function of tension rods is combining steel supports into a whole body along longitudinal direction to avoid the tilt of steel supports, and improve the stability and bearing capacity of steel supports. There are various tension rods, including angle steel bar, flat steel plate, round steel bar, steel pipe and adjustable rod.

Backfilling behind supports can improve the loading state of steel supports, and greatly enhance their bearing capacity (Luo 2009; Xie et al. 2010). Backfilling was applied in the roadways surrounded by soft rocks in the Huainan and the Tiefa coal mining districts, compared with the case without backfilling, the working resistance of steel supports increased by 5 times, the roadway displacement decreased by $90 \%$. Therefore, for roadways at depth and under complex conditions, backfilling is necessary to fill the gap behind the yieldable steel supports.

\subsubsection{New developments of steel supports}

New steel support types developed in recent years are the steel pipe support filled with concrete, the steel support with active setting force, and so on.

3.2.2.1 Steel pipe support filled with concrete The steel pipe support filled with concrete is made of steel pipes and concrete. On one hand, the steel pipe filled with concrete 


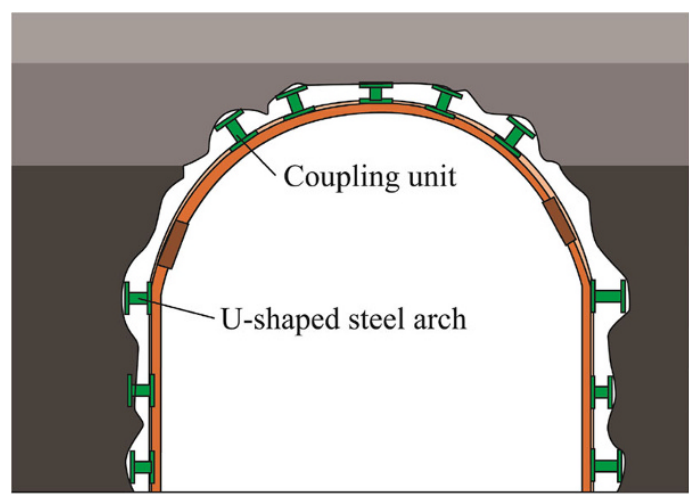

(a)

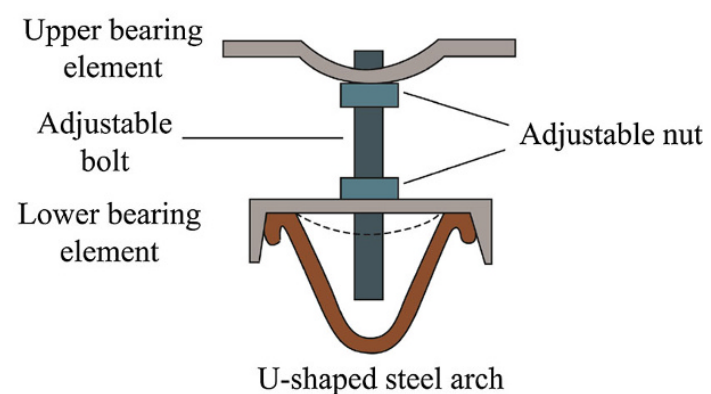

(b)

Fig. 10 Structure of active steel support (Chen et al. 2013). a schematic drawing of on-site installation $\mathbf{b}$ coupling unit

can increase its stability; on the other hand, the pipe containment makes concrete in tri-directional compressive stress state, increases the concrete compressive strength and stiffness, and greatly improves the bearing capacity of the steel pipe support filled with concrete.

In view of the above-stated advantages of the steel pipe support filled with concrete, Chinese researchers developed the high strength steel pipe support filled with concrete, which is applicable to the roadways at depth or surrounded by soft rocks (Gao et al. 2010; Li et al. 2013), as shown in Fig. 9. The maximum bearing load of the steel pipe support filled with concrete (an enclosed form consisting of four segments, seamless steel pipes with dimensions of $\varphi 140 \mathrm{~mm} \times 4.5 \mathrm{~mm})$ is beyond $1,500 \mathrm{kN}$. Theoretical analyses showed that the maximum bearing load of a short steel pipe filled with concrete is much larger than that of a short section of U-shaped steel. Applications in many underground coal mining areas showed that the steel pipe support filled with concrete can effectively control the severe deformation of roadways at depth, surrounded with soft rocks, and affected by mining disturbances.

3.2.2.2 Steel support with active setting force All traditional steel supports belong to passive supporting form, unlike pretensioned rock bolts and cables, which can control the initial separation and damage of rocks. Therefore, some researchers developed the active steel support (Chen et al. 2013). The structure of the active steel support is shown in Fig. 10. It is composed of the common steel support and the coupling units. The coupling unit consists of the upper bearing element (plate), the adjustable high strength bolt, and the lower bearing element (channel steel). Screwing the nut on the high strength bolt can provide an active setting force $(20-50 \mathrm{kN})$, which is favorable to control the initial roadway deformation. Besides above stated functions, the coupling units can adjust and balance the unevenly distributed load from rocks, improve the loading state of the U-shaped steel support, and enhance its bearing capacity.

\subsection{Grouting}

Grouting is an effective method to reinforce the broken rocks surrounding roadways. The purpose of grouting is to enhance the integrity and strength of surrounding rocks, improve their mechanical performance and stability, and avoid or reduce roof collapses and rib spalling.

There are a variety of grouting methods: pre-grouting and post-grouting dependent on the grouting time relative to roadway driving; cement grouting, clay grouting, and chemical grouting according to grouting materials; single formula grouting and double formula grouting based on the grouting procedures; backfilling grouting, permeating grouting, squeezing grouting, splitting grouting, and high pressure jet grouting according to the geological conditions, the grouting spreading and permeating properties.

\subsubsection{Functions of grouting}

There are three main functions for grouting to reinforce rocks surrounding roadways (Kang and Feng 2013).

(1) Increasing strength and stiffness of interfaces in surrounding rocks. The strength and deformation of surrounding rocks with maturely developed interfaces mainly depend on the mechanical properties of the interfaces. In general, the strength and stiffness of the interfaces are lower than those of rock blocks, and separation, slipping and opening occur easily along the interfaces, which can bring about dilatant deformation of surrounding rocks. Grouting can greatly improve strength and stiffness of the interfaces, thus increase the integral strength of surrounding rocks and their load bearing capacity.

(2) Filling and compacting cracks. Slurry can be filled in some cracks under grouting pressure, and even the cracks unfilled by slurry can be closed with the grouting pressure, which will decrease the rock 
Table 2 Properties of silicate modified polyurethane grouting material

\begin{tabular}{llll}
\hline Item & & Index & \\
\hline Slurry performance & Constituent & A & B \\
& Appearance & Colorless liquid & Deep brown transparent liquid \\
& Viscosity $(\mathrm{mPa} . \mathrm{s})$ & $250-350$ & $150-250$ \\
& Flash point $\left({ }^{\circ} \mathrm{C}\right)$ & & $>190$ \\
& Volume ratio & $\mathrm{A}: \mathrm{B}=1: 1$ & $2-5$ \\
Reaction performance & Flowing time $(\min )$ & Non-inflammability \\
& Inflammability & $<90$ & Non-foaming \\
& Max reaction temperature $\left({ }^{\circ} \mathrm{C}\right)$ & $\geq 40$ & $\geq 7.0$ \\
& Foaming & $\geq 3.0$ \\
\hline
\end{tabular}

porosity, improve the stress distribution around the pores and cracks, and enhance rock strength.

(3) Sealing water and air. Grouting can effectively block the water passage in surrounding rocks, avoid or reduce water-softening effect on rocks. At the same time, grouting can fill the cracks, and prevent rocks from weathering.

\subsubsection{Grouting materials}

Grouting materials can be divided into three groups: cement grouting materials, chemical grouting materials, and compound grouting materials. The main performance indexes of grouting materials include slurry viscosity, mechanical properties, and permeability. In addition, flame-retardant and antistatic properties must be stressed for underground coal mines.

3.3.2.1 Cement grouting materials Cement grouting materials have characteristics of high strength, durability, non-polluting, ample source, simple grouting equipment, and low costs, which have been widely used in various applications. However, cement grouting materials also have some disadvantages: easily isolating and depositing, poor stability, large grain size difficult to fill the microcracks or pores, limited spreading range; uncertain setting time, low initial strength. Cement grouting materials are applicable to reinforce the roadways in loose and broken rocks with no strict need for time, such as rocks around main roadways, chambers, and gateroads.

To overcome the faults of common cement grouting materials, ultrafine cement grouting materials were developed in China and other countries (Hou et al. 2013). Such as the ultrafine cement grouting material, MC-100, the specific surface area amounts to $1,300 \mathrm{~m}^{2} / \mathrm{kg}$, and the content of grains with size more than $7.8 \mu \mathrm{m}$ is below $3 \%$. The main advantages of ultrafine cement grouting materials are easy injection, good permeability to fill micro-cracks, high cohesion, low porosity, good durability and anti-permeability. Therefore, the ultrafine cement is one kind of very promising grouting materials.

3.3.2.2 Chemical grouting materials In general, chemical grouting materials are made of polymers with low viscosity, good grouting performance, high permeability, capability to fill in micro-cracks or pores. Besides, chemical materials cure fast, and curing time is adjustable, therefore, they are frequently used in projects demanding for time or on emergent occasions.

Common chemical grouting materials include water glass, epoxy, n-methylolacrylamide, acrylamide, acrylate, polyester, lignin, urea-formaldehyde, phenol-formaldehyde and polyurethane (Feng and Kang 2009, 2010). In recent years, the geological and mining conditions become more and more complicated, and broken rocks occur frequently. Therefore, the chemical grouting materials, particularly the polyurethane grouting material, are widely used in underground coal mines to deal with rib spalling and roof collapse,.

In order to deal with the issues associated with the high cost and inflammability of the polyurethane grouting material, modifications have been carried out by adding silicate in traditional polyurethane grouting material (Feng et al. 2013). The new material not only keeps the excellent mechanical performances of polyurethane, but also overcomes the problem of inflammability, which is applicable to reinforce rocks surrounding roadways. The physical and mechanical properties of this grouting material developed by Coal Mining and Designing Branch, China Coal Research Institute are listed in Table 2. 


\subsubsection{Grouting parameters and procedures}

The geological and mining conditions, such as project purpose, rock type and structures, should be fully understood before grouting practices, as result of which then reasonable grouting materials, procedures and parameters can be determined. Grouting parameters include grouting time, pressure, volume, spreading radius, and borehole pattern, and all these parameters affect the grouting performance to some extent.

3.3.3.1 Grouting time Grouting time denotes the cumulative time needed for grouting. For rocks with fully developed fractures or pores, the grouting time should be controlled not too long to prevent the slurry leaking into roadways, while the grouting pressure and quantity should also be controlled. For rocks with less developed fractures, in which the slurry is taken in slowly and diffused hardly, it is necessary to extend the grouting time to improve grouting performance.

3.3.3.2 Grouting pressure Grouting pressure is the driving force that causes slurry to diffuse into the rocks, and it obviously affects the grouting quality and performance. The selection of the grouting pressure is influenced by ground conditions, grouting materials, grouting procedure, and so on. If a very high grouting pressure is adopted, splitting grouting will take place resulting in the rib spalling or roof collapse. If the grouting pressure is too low, it is difficult to make the slurry diffuse into the rocks.

Choosing grouting pressure is mainly dependent on rock permeability, grouting scope in need, and slurry properties. For cement slurry, if rocks are seriously broken, $0.5-1 \mathrm{MPa}$ is the proper grouting pressure; if rock are moderately broken, $1-2 \mathrm{MPa}$ is the proper grouting pressure; and if rocks are less broken, 2-5 MPa is the proper grouting pressure. For the rocks with very low strength, the grouting pressure should not exceed one third of the rock compressive strength.

3.3.3.3 Grouting quantity The rock capacity of taking in slurry varies greatly due to different rock properties, fractures, broken scopes. Meanwhile, it is also affected by grouting pressure, grouting time, and so on. To fill the fractures fully, the guideline for grouting quantity is that grouting does not finish until rocks cannot take in more slurry.

3.3.3.4 Diffusing radius The diffusing radius is the foundation to determine grouting borehole parameters (density and depth). The diffusing radius of slurry in rocks is usually scattered, it will increase as rock permeability, fracture width, grouting pressure and grouting time increase and it will decrease as slurry concentration and

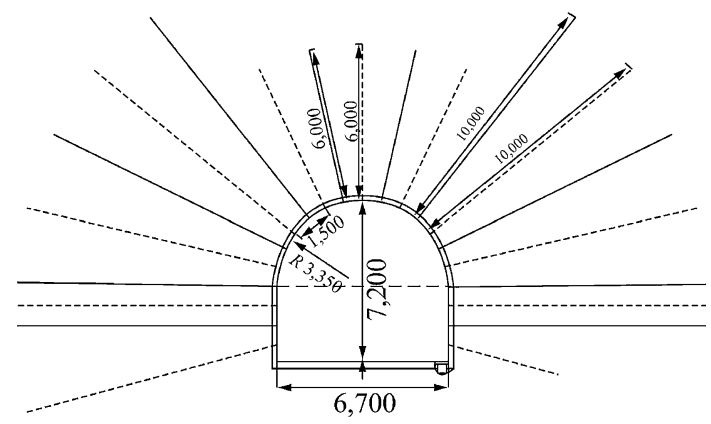

Fig. 11 Borehole layout pattern for grouting in belt driving chamber of the Chengzhuang coal mine, Jincheng

viscosity increase. The diffusing scope of slurry can be controlled by adjusting grouting pressure, quantity, and concentration.

3.3.3.5 Grouting borehole parameters Grouting borehole parameters involve row spacing, spacing in one row of boreholes and their depth. The selection of row spacing and spacing in one row of boreholes is closely related to grouting diffusing radius. The diffusing radius of each grouting borehole should overlap partly that of the adjacent grouting borehole, or the borehole spacing should be less than two times the diffusing radius with a coefficient of $0.65-0.7$. The depth of grouting boreholes should reach the borders of broken areas.

\subsubsection{Case study}

The belt conveyer chamber in No. 2 mining panel, the Chengzhuang coal mine, the Jincheng coal mining district, is $440 \mathrm{~m}$ below the surface. The immediate roof is fine sandstone, $1.37 \mathrm{~m}$ thick, and the main roof is medium sandstone, $7.33 \mathrm{~m}$ thick. The belt conveyer chamber with a cross-section of semi-circle arch, was supported by rock bolts, cables and shotcrete. There were many roadways and a coal face around the belt conveyer chamber, so it had experienced the dynamic loads from adjacent roadway driving and face mining. The rocks surrounding the belt conveyer chamber deformed and damaged severely with fully developed fractures and a broken zone 8-10 m deep.

Grouting practices were carried out in the rocks surrounding the belt conveyer chamber in full cross-section. Silicate cement No.525 with XPM additive was applied under normal working conditions. If slurry leaked in a large area, cement and water glass were applied. The layout of grouting boreholes in belt driving chamber is shown in Fig. 11. The row spacing of boreholes is $2 \mathrm{~m}$, and the spacing in one row is $1.5-1.8 \mathrm{~m}$. The borehole diameter is $56 \mathrm{~mm}$, the boreholes in the center of roof are $6 \mathrm{~m}$ deep, 
and the other are $10 \mathrm{~m}$ deep. The final grouting pressure is 4-6 MPa. At the same time, grouting practices were carried out in the floor.

After the belt conveyer chamber was reinforced by grouting mentioned above, the grouted surrounding rocks were exposed by trimming the sides and excavating base pits. The surveying results pointed out: when the slurry is filled and imbedded in rock fractures, the grouted bodies with varying sizes and different numbers of rock fragments are formed, and the integrity and compressive strength of the grouted rocks are greatly improved. The chamber was also reinforced by rock bolts and cables after the grouting practices. The monitoring data showed that the floor heave is less than $10 \mathrm{~mm}$, the side-to-side convergence was less than $5 \mathrm{~mm}$, and the deformation of the chamber was effectively controlled.

\subsection{Combined supports}

If a single support type cannot effectively control the roadway deformation, combined support method, i.e. the combination of two or more support types are used, which is an alternative for roadways at depth and under complex conditions. There are various combined supports, such as rock bolting and grouting, rock bolting and steel supports, steel supports and grouting, rock bolting with grouting and steel supports. If only the advantages of each support method are fully exerted, and different support methods compensate each other, good support performance can be realized. Two combined supports, rock bolting and grouting, rock bolting and steel supports commonly used in complex roadways, are detailed as follows.

\subsubsection{Rock bolting and grouting}

When roadways are driven in broken rocks, rock bolting is not effective to control roadway deformations because of poor anchoring performance and low bearing capacity of bolts. Besides, when damaged roadways are repaired or overhauled, rock bolting can also hardly get good reinforcement performance. Combination of rock bolting and grouting is a promising approach to solve the reinforcement problems stated above.

\subsubsection{Combination forms of rock bolting and grout-} ing There are two combination forms of rock bolting and grouting: one is grouting first, then installing rock bolts and cables; another is grouting and bolting at the same time using pipe grouting bolts, which are not only used as grouting tubes to inject slurry, but also the bolts anchored by slurry. Based on the characteristics of roadways in coal mines, many kinds of grouting bolts have been developed (Wang et al. 2005). For extremely broken rocks, the self-

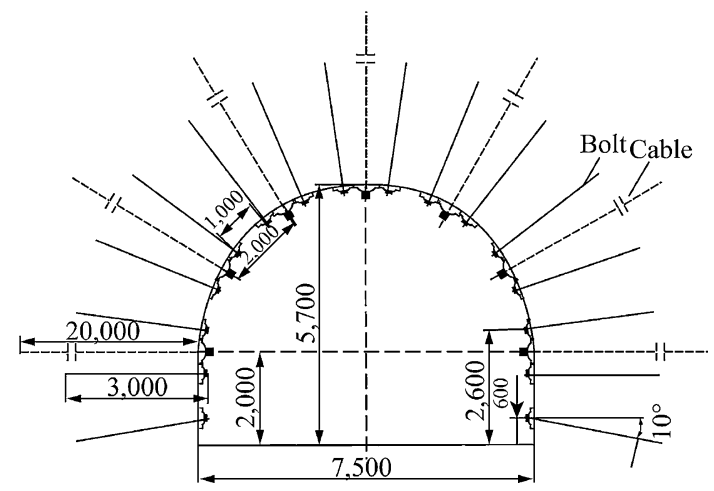

Fig. 12 Layout pattern of rock bolts and cables for north horsehead in the Tunliu coal mine, Luan

boring grouting bolts have been invented. These bolts are used as boring rods and grouting tubes at the same time, and provide an effective way to solve the problem of borehole caving in the extremely broken rocks (Lu 2003). On the basis of the pretension resin cable with small borehole, the cable anchored with resin capsules and grout slurry was developed. The rock grouting can be achieved through adjusting the grouting parameters (Wu et al. 2001; Kang et al. 2003).

3.4.1.2 Case study The auxiliary shaft in the Tunliu coal mine, the Luan coal mining district, is $600 \mathrm{~m}$ deep. The rocks around the cross point of the auxiliary shaft and the underground station, are clay-stone and siltstone intermingled with layers of thin coal seam. There exist a few of small faults nearby, and the rocks belong to the typical broken type. Based on thoroughly geomechanics tests around the group of chambers, the spatial characteristics and law of the stress distribution around the chambers were studied, the characteristics of chamber deformation and damage were also researched. Finally, a reinforcement pattern for the group of chambers was proposed: firstly, high pressure grouting with deep boreholes; then rock bolting with extra high strength bolts and cables; finally, sealing chamber surface with shotcreting (Kang et al. 2011c).

Cement slurry was used as the grouting material under normal conditions, where fractures opened widely, cement with water glass was used. Cement slurry was made of silicate cement No.525 with XPM additive. The row spacing of boreholes was $3 \mathrm{~m}$ with spacing in one row of $2 \mathrm{~m}$. The grouting pressure was about $6 \mathrm{MPa}$.

The extra high strength bolts were 2.4-3 m long with a yield strength of $600 \mathrm{MPa}$, a tensile strength of $800 \mathrm{MPa}$, anchored by resin capsules. The installing torque moment on bolts was 500 N.m. The bolt row spacing and the spacing in one row were $1 \mathrm{~m}$. The diameter of cables was $19 \mathrm{~mm}$ with a broken force of $400 \mathrm{kN}$. The cables in the 


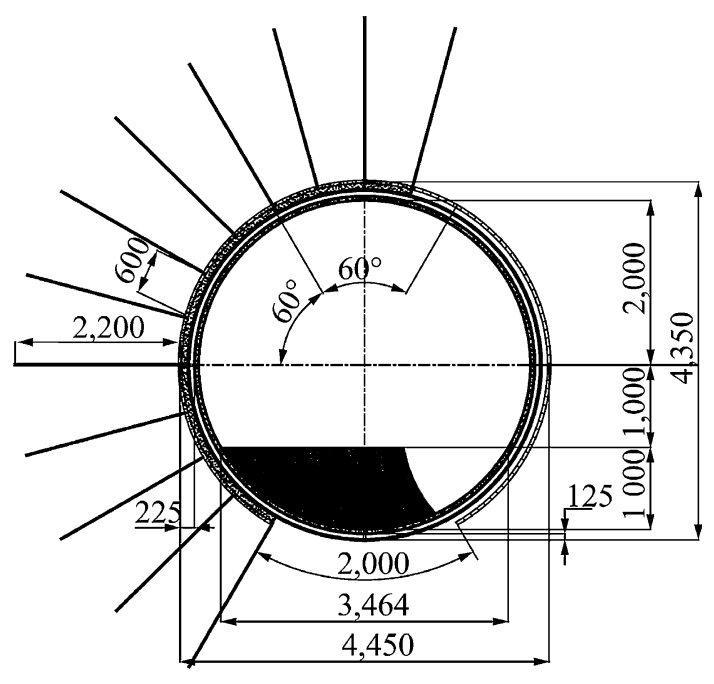

Fig. 13 Support pattern for gateroad in the Xiaokang coal mine, Tiefa

roof and sides were $20 \mathrm{~m}$ long, anchored by resin capsules and cement slurry with a pretension of $200 \mathrm{kN}$. The cable row spacing and the spacing in one row were $2 \mathrm{~m}$. The reinforcement pattern of the north horsehead is shown in Fig. 12.

After the above reinforcement pattern was carried out, there was no obvious deformation in the horsehead roof, the side-to-side convergence was less than $30 \mathrm{~mm}$, the floor heave was less than $24 \mathrm{~mm}$ and the horsehead kept stable. The combination of bolts and cables with grouting, effectively controlled the deformation and damage of rocks surrounding the group of chambers, and kept the chambers in a stable state for a long term.

\subsubsection{Rock bolting and steel supports}

\subsubsection{Combination forms of rock bolting and steel sup-}

ports The combination of rock bolting and steel supports is commonly used in complex roadways. According to the construction sequence, this combination support can be divided into two types: one is installing bolts (or cables) first, then setting steel supports; another is setting steel supports first, then installing bolts (or cables) between the steel supports. Bolts and cables can be used with various steel supports, such as I-shaped steel supports, yieldable steel arches, and enclosed steel supports. Bolts or cables can individually be combined with steel supports (Tian et al. 2011), bolts and cables can also be together used with steel supports.

The installing time of bolts and cables needs to be stressed especially. Bolts and cables should be installed before obvious separation and damage occur in the rocks to fully exert their reinforcement functions. Otherwise, the bolting performance will be seriously decreased when bolts and cables are installed in the rocks with obvious separation and damage.

3.4.2.2 Case study The Xiaokang coal mine in the Tiefa coal mining district, is a typical coalmine with high stresses, severely swelling and soft rocks. The rock deformation has following features: loading fast, high pressure, high deformation velocity, large amount of deformation, and long deformation time, which caused a great difficulty for the roadway support. A gateroad in a top coal caving fully mechanized face, was driven along the floor of the coal seam with a buried depth of $509-555 \mathrm{~m}$. The coal seam was $8.4 \mathrm{~m}$ thick, and its compressive strength was $17.6 \mathrm{MPa}$. The cross section of the gateroad was a circle with a net width of $4.0 \mathrm{~m}$, and a net height of $3.0 \mathrm{~m}$.

The roadway support pattern, the combination of bolts and shotcrete with U-shaped yieldable steel supports, was determined on the basis of surrounding rock conditions. The bolt was $2.2 \mathrm{~m}$ long with a diameter of $20 \mathrm{~mm}$, anchored with resin capsules. The row spacing was $600 \mathrm{~mm}$ and the spacing in one row was $800 \mathrm{~mm}$. The yieldable circular steel supports were made of $29 \mathrm{U}$ steel, composed of six segments, each of which was $4 \mathrm{~m}$ long. The spacing of steel supports was $600 \mathrm{~mm}$. A shotcreting layer $100 \mathrm{~mm}$ thick was sprayed after the steel supports were installed. The gateroad support pattern is shown in Fig. 13.

The gateroad convergences were monitored during gateroad driving and face retreating periods. During whole service time of the gateroad, the roof-to-floor and side-toside convergences were 436 and $623 \mathrm{~mm}$ respectively. The gateroad kept stable, and no repairing work was needed.

\section{Conclusions and prospects}

(1) The geological and mining conditions for roadways in Chinese coal mines have following characteristics: low rock strength, complex geological structures, maturely developed joints and bedding planes, large depth; narrow pillars, strong mining disturbances. These characteristics bring about a series of complex roadways, such as ones surrounded by soft rocks, ones surrounded by broken rocks, ones suffering high stresses, ones driven along gob area and retained along gob-side. It is very difficult to support these roadways using traditional methods, and more advanced support techniques are needed.

(2) The roadway support technology in Chinese coal mine had gone through a history of timbering, lining, steel arch supports and rock bolting. Rock bolts and 
cables have been the mainstream support method. However, there are still many other support methods, such as steel supports, grouting and combination supports used in some conditions.

(3) Rock bolting in Chinese coal mines has gone through a process from low strength, high strength, to high pretension and extra high strength. In the matter of rock bolting theories, it was realized that the intrinsic bolting function is to control rock dilatant deformations, keep rock integrity and continuity, and prevent rock strength from decreasing. The bolting theory with high pretension and extra high strength was proposed, which emphasizes the decisive roles of bolt pretension and its spreading into rocks. The bolting system with high pretension and extra high strength can reinforce complex roadways once for all. The complete rock bolting technology based on rock geomechanics tests has been developed, which provide a support method with top priority and effectiveness for roadways under complex conditions.

(4) For roadways in weak and broken rocks, waterbearing rocks, or water softening and swelling rocks, deep roadways with high stresses and creep effect, and roadways suffering strong mining disturbances, steel supports are irreplaceable. Through continuous studies and practices, some new types of steel supports, such as steel pipe supports filled with concrete and steel supports with active setting force were developed. The mechanical performances, structures and accessories of steel supports have been improved.

(5) Grouting is an effective method to reinforce the broken rocks surrounding roadways. Many new grouting materials were developed. To overcome the faults of common cement grouting materials, ultrafine cement slurry was developed with good permeability, high cohesion and durability. Chemical grouting materials, such as polyester, urea-formaldehyde and polyurethane grouts, were also developed and widely used in underground coal mines. A new compound grouting material with polyurethane and silicate was also developed to improve grouting mechanical properties, and reduce costs.

(6) Combination supports, including rock bolting and grouting, rock bolting and steel supports, steel supports and grouting, rock bolting with grouting and steel supports, are effective approaches for roadways under complex conditions. If the advantages of each support method are fully exerted, and various support methods compensate each other, good support performance can be realized.
Although the achievements and developments mentioned above have been made in roadway support technologies, there are still a lot of researches need to be done in the future. The geomechanics measurements for deep and complex roadways should be strengthened to further understand underground geological and stress environments; the deformation and damage mechanism of complex roadways should be further deeply studied and interaction between surrounding rocks and supports should be more clearly expounded; the supporting technologies for roadways surrounding with extra soft rock or extra broken rock, roadways with intense floor heave, and roadways with rock burst, need to be developed to solve the associated roadway support problems.

Open Access This article is distributed under the terms of the Creative Commons Attribution License which permits any use, distribution, and reproduction in any medium, provided the original author(s) and the source are credited.

\section{References}

Bai JB, Wang WJ, Hou CJ, Huang HF (2000) Control mechanism and support technique about gateway driven along goaf in fully mechanized top coal caving face. J China Coal Soc 25(5):478-481 (in Chinese)

Cai MF, Peng H, Qiao L, Ma XM (2008) Distribution law of in situ stress field and its relationship to regional geological structures in Wanfu coal mine. J China Coal Soc 33(11):1248-1252 (in Chinese)

Chen XN, Wang AH, Zhang K (2013) Experimental research on coupling device of U-steel support-surrounding rock stress. Coal Sci Technol 41(12):4-7 (in Chinese)

Dong FT, Song HW, Guo ZH, Lu SM, Liang SJ (1994) Roadway support theory based on broken rock zone. J China Coal Soc 19(1):21-32 (in Chinese)

Feng ZQ, Kang HP (2009) Technology research of chemical grouting for cracked coal-rock mass and demonstration project. J Yangtze River Sci Res Inst 26(7):60-65 (in Chinese)

Feng ZQ, Kang HP (2010) Development and application of new waterproof grouting materials of polyurethane. Chin J Geotech Eng 32(3):375-380 (in Chinese)

Feng ZQ, Kang HP, Han GQ (2013) Polyurethane grouting material modified by inorganic salts in coal mine. Chin J Geotech Eng 35(8):1559-1564 (in Chinese)

Gale WJ, Blackwood RL (1987) Stress distribution and rock failure around coal mine roadway. Int J Rock Mech Min Sci \& Geomech Abstr 24(3):165-173

Gale WJ, Fabjanczyk MW, Terrant GC (1992) Optimization of reinforcement design of coal mine roadways. In: Proceeding of 11 th conference on ground control in mining, Wollonong, Australia, 212-219

Gao YF, Wang B, Wang J, Li B, Xing F, Wang ZG, Jin TL (2010) Test on structural property and application of concrete-filled steel tube support of deep mine and soft rock roadway. Chin J Rock Mech Eng 29(Supp 1):2604-2609 (in Chinese)

Gray PA, Hawker R, Sykes A, Tadolini SC (2010) New development in self drilling rock bolt technology. In: The 29th international conference on ground control in mining, Morgantown 
He MC, Yuan HS, Jing HW, Wang FR, Jing HH (2004) Theory and practice of bolt supporting in China coal mines. Science Press, Beijing (in Chinese)

Hou CJ, Gou PF (2000) Mechanism study on strength enhancement for the rocks surrounding roadway supported by bolt. Chin J Rock Mech Eng 19(3):342-345 (in Chinese)

Hou CJ (2013) Ground control of roadways. China University of Mining and Technology Press, Xuzhou

Hu SR, Peng JC, Huang C, Chen PK, Li M (2011) An overview of current status and progress in coal mining of the deep over a kilometer. China Min Mag 20(7):105-110 (in Chinese)

Hudson JA, Harrison JP (2009) Engineering rock mechanics (an introduction to the principles). Translated by Feng XT, et al. Science Press, Beijing, 220-234 (in Chinese)

Hutchinson DJ (2000) Observational design of underground cable bolt support systems utilizing instrumentation. Bull Eng Geol Environ 58(3):227-241

Jing HW, Song HW, Guo ZH (1999) Study of deformation mechanism of broken zone around soft rock roadway and its control technique. J China Univ Min Technol 28(6):560-564 (in Chinese)

Ju WJ (2000) Monitoring technology for rock bolting engineering. J Chnia Coal Soc, 25(Supp.): 58-61 (in Chinese)

Kang HP (2002) Dynamic and informational rock bolting design method for coal roadway and its application[J]. Coal Min Technol 1:5-8 (in Chinese)

Kang HP, Feng ZQ (2013) Status and development tendency of roadway grouting reinforcement technology in coal mine. Coal Min Technol 18(3):1-7 (in Chinese)

Kang HP, Wang JH (2007) Rock bolting theory and complete technology for coal roadways. China Coal Industry Publishing House, Beijing (in Chinese)

Kang HP, Lin J, Zhang BC (2003) Study of small borehole pretensioned cable reinforcing complicated roadway. Chin $\mathrm{J}$ Rock Mech Eng 22(3):387-390 (in Chinese)

Kang HP, Jiang TM, Gao FQ (2007a) Effect of pretensioned stress to rock bolting. J China Coal Soc 32(7):673-678 (in Chinese)

Kang HP, Wang JH, Lin J (2007b) High pretensioned stress and intensive bolting system and its application in deep roadways. J China Coal Soc 32(12):1233-1238 (in Chinese)

Kang HP, Wang JH, Gao FQ (2009a) Stress distribution characteristics in rock surrounding heading face and its relationship with supporting. J China Coal Soc 34(12):1585-1593 (in Chinese)

Kang HP, Lin J, Wu YZ (2009b) High pretensioned stress and intensive cable bolting technology set in full section and application in entry affected by dynamic pressure. J China Coal Soc 34(9):1153-1159 (in Chinese)

Kang HP, Lin J, Wu YZ (2009c) Development of high pretensioned and intensive supporting system and its application in coal mine roadways. In: The 6th international conference on mining science \& technology, Xuzhou, 479-485

Kang HP, Zhang X, Si LP, Wu YZ, Gao FQ (2010a) In-situ stress measurements and stress distribution characteristics in underground coal mines in China. Eng Geol 116:333-345

Kang HP, Si LP, Zhang X (2010b) In-situ stress measurements in underground coal mines and study on stress fields//rock stress and earthquakes: Proceedings of the Fifth international symposium on In-situ rock stress, Beijing, 149-154

Kang HP, Niu DL, Zhang Z, Lin J, Li ZH, Fan MJ (2010c) Deformation characteristics of surrounding rock and supporting technology of gob-side entry retaining in deep coal mine. Chin J Rock Mech Eng 29(10):1977-1987 (in Chinese)
Kang HP, Lin J, Si LP (2010d) Analysis on characteristics of roadway deformation in deep coal mines and its reinforcement case studies. In: Proceedings of the Fifth international seminar on deep and high stress mining, Santiago, Chile, 77-88

Kang HP, Wang JH, Lin J (2011a) Reinforcement technique and its application in complicated roadways in underground coal mines//harmonising rock engineering and the environment: Proceeding of 12th ISRM international congress on rock mechanics, Beijing, 1527-1532

Kang HP, Wu YZ, Gao FQ (2011b) Deformation characteristics and reinforcement technology for entry subjected to mining-induced stresses. J Rock Mech Geotech Eng 3(3):207-219

Kang HP, Lin J, Yang JH, Wu YZ, Gao FQ (2011c) Stress distribution and synthetic reinforcing technology for chamber group with soft and fractured surrounding rock. Chin J Geotech Eng 33(5):808-814 (in Chinese)

Kang HP, Yan LX, Guo XP, Zhang ZT, Gao FQ (2012) Characteristics of surrounding rock deformation and reinforcement technology of retained entry in working face with multi-entry layout. Chin J Rock Mech Eng 31(10):2022-2036 (in Chinese)

Li XB, Yang RS, Gao YF, He XS Wang C (2013) High-strength steel tubular confined concrete supports support technology for large section soft rock inclined shaft. J China Coal Soc 38(10): 1742-1748 (in Chinese)

Lu HW (2003) Study of reinforcement technique combined drilling, anchoring and grouting together in fractured coal and rock, Master's thesis. China Coal Research Institute, Beijing (in Chinese)

Luo Y (2009) Research on backfill technology with U-steel support in soft rock roadway in deep mine. Chin Q Mech 30(3):488-494 (in Chinese)

Peng SS, Tang DHY (1984) Roof bolting in underground mining: a state-of-the- art review. Int J Min Eng 2:1-42

Shi YW, Zhang ST, Yin SK, Rui SS, Li CX (2009) The strata control technology for deep coal mining at home and abroad. China Coal Industry Publishing Hous, Beijing (in Chinese)

Shi YW, Qi QX, Gu QZ (2013) Study on rock burst prevention and ground control in coal mine abroad. China Coal Industry Publishing House, Beijing (in Chinese)

Song G, Stankus JC (1997) Control mechanism of a tensioned bolt system in the laminated roof with a large horizontal stress. In: The 16th international conference on ground control in mining. Morgantown, West Virginia, 167-172

Tian L, Xie WB, Jing SG, Xing YD, Peng JP (2011) Framed timber and anchor coupling collective support technology for fully mechanized top coal mining face crossing over gateway. Coal Sci Technol 39(11): 44-47, 62 (in Chinese)

Villaescusa E, Schubert CJ (1999) Monitoring the performance of rock reinforcement. Geotech Geol Eng 17(3):321-333

Wang LG, Li MY, Wang XZ (2005) Study of mechanisms and technology for bolting and grouting in special soft rock roadways under high stress. Chin J Rock Mech Eng 24(16):2889-2893 (in Chinese)

Wu ZX, Zhao YL, Liang JJ, Li AH, Li GX (2001) Pre-stressed grout bolting technology applied to reinforcement of mine large cross section roadway. Coal Sci Technol 29(8):10-12 (in Chinese)

Xie WB, Jing SG, Wang T, Ren YK, Zhang N (2010) Structural stability of U-steel support and its control technology. Chin J Rock Mech Eng 29(Supp. 2):3743-3748 (in Chinese)

Zhang N, Gao MS (2004) High-strength and pretension bolting support of coal roadway and its appication[J]. J China Univ Min Technol 33(5):524-527 (in Chinese) 